\title{
AQÜÍFERO GUARANI:
}

\section{A FUNDAMENTALIDADE DO DIREITO À ÁGUA E SUA TITULARIDADE DIFUSA}

\author{
Gabriel Gualano de Godoy - Direito UFPR \\ Mestrando em Direito da UFPR, bolsista da Capes-MEC e pesquisador do Núcleo de Direitos \\ Humanos e Democracia \\ e-mail: gabrielgualano@hotmail.com
}

RESUMO: Os direitos difusos visam à proteção de interesses que não se inserem perfeitamente no standard individualista cunhado pela modernidade e representam uma projeção de anseios sociais pela tutela de bens que não são nem meramente individuais nem sequer coletivos, mas sim pertinentes a cada ser humano e a todos ao mesmo tempo. A alguns direitos difusos, como o direito a um meio ambiente equilibrado, reputa-se o caractere de herança intergeracional: impõe-se ao ordenamento jurídico a tutela dos interesses das gerações futuras. É dessa forma que 0 presente trabalho vislumbra a relação entre o homem e o meio ambiente, entre o homem e o Aqüífero Guarani. Fenômenos próprios da contemporaneidade como a industrialização, a urbanização e o elevado crescimento populacional demonstram que os recursos hídricos, até há bem pouco tempo considerados inesgotáveis, na realidade não o são. Torna-se, então, premente a busca por uma nova racionalização do acesso e utilização do Aqüífero Guarani, a maior reserva subterrânea de água doce do mundo. Conclui-se, portanto, que toda proposta de aproveitamento do Aqüífero Guarani leve em consideração a fundamentalidade do direito à água e sua titularidade difusa.

PALAVRAS-CHAVE: Aqüífero Guarani; Direitos socioambientais; Direitos difusos. 


\section{ÁGUA DOCE E SUA ESCASSEZ}

A água é um elemento essencial e indispensável à vida de todo ser humano, além de substância imprescindível ao ecossistema.

Contudo, apesar do planeta Terra ser coberto por volta de 1.400 milhões de $\mathrm{Km}^{3}$ de água, apenas cerca de $2 \%$ desse valor corresponde à quantidade total de água doce encontrada no mundo.

Na verdade, a maior parte da água doce encontra-se nas calotas polares, sendo que menos de $1 \%$ corresponde a quantidade disponível nos rios, lagos e no subsolo para ser utilizada nos setores agrícola e industrial, além da parcela necessária à sobrevivência de cada ser humano.

\section{DIREITO FUNDAMENTAL À ÁGUA}

A proteção da água, em todos os seus rudimentos indispensáveis à vida e à conservação do equilíbrio da natureza, quer salvaguardar a qualidade do meio ambiente $^{2}$ em função da qualidade de vida.

O direito à água compõe o direito ao meio ambiente ecologicamente equilibrado, sendo, portanto, um prolongamento do direito à vida, e configurando-se, também, como direito fundamental.

Tal "novo" direito fundamental parece ter sido consagrado, igualmente, na Declaração do Meio Ambiente adotada pela Conferência das Nações Unidas, em Estocolmo, em junho de 1972, cujos 26 princípios constituem prolongamento da Declaração Universal dos Direitos do Homem.

${ }^{1}$ CLARKE, R. \& KING, J. The Water Atlas. New York: The New Press, 2004.

2 José Afonso da SILVA define o meio ambiente como sendo a interação do conjunto de elementos naturais, artificiais e culturais que propiciem o desenvolvimento equilibrado da vida em todas as suas formas. In: SILVA, José Afonso da. Direito Ambiental Constitucional. 3. ed. São Paulo: Malheiros, 2000. p. 36. 


\section{DIREITOS DIFUSOS}

Costuma-se dizer que os direitos difusos são produtos de movimentos sociais eclodidos na virada da década de 50 para 60, representados, principalmente, pela luta das mulheres, dos negros e dos ambientalistas.

O surgimento dos direitos difusos ocorre em um momento de reconhecimento dos interesses de uma sociedade que vive um desenvolvimento econômico e tecnológico mais vasto e intenso do que o período em que se consagrou a materialização do direito privado e dos direitos individuais.

Norberto Bobbio explicaria o surgimento do direito ao meio ambiente como tendo sido "uma passagem da consideração do indivíduo humano uti singulus, que foi o primeiro sujeito ao qual se atribuíram direitos naturais (ou morais) - em outras palavras, da 'pessoa' -, para sujeitos diferentes do indivíduo, como a família, as minorias étnicas e religiosas, toda a humanidade em seu conjunto (como no atual debate entre filósofos da moral, sobre o direito dos pósteros à sobrevivência); e, além dos indivíduos humanos considerados singularmente ou nas diversas comunidades reais ou ideais que os representam, até mesmo para sujeitos diferentes dos homens, como os animais". ${ }^{3}$ Entretanto, os interesses coletivos e difusos $^{4}$ não constituem uma categoria essencialmente distinta dos direitos fundamentais, mas criam uma nova perspectiva de proteção geral, constituindo-se em interesses que legitimam a comunidade na invocação da tutela jurisdicional. ${ }^{5}$

Interessante verificar que o Código de Defesa do Consumidor fornece um conceito de interesses ou direitos difusos, em seu art. 81, inciso I, como sendo: "os

${ }^{3}$ BOBBIO, Norberto. A Era dos Direitos. Tradução de Carlos Nelson Coutinho. 12. ed. Rio de Janeiro: Campus, 1992. p. 69.

${ }^{4}$ É importante ressaltar que existe diferença entre Direitos Coletivos e Direitos Difusos, noção não estabelecida por CAPELETTI, um dos pioneiros no estudo dos interesses difusos das massas. Direitos coletivos são próprios de determinadas categorias específicas de pessoas, decorrem de uma base social concreta. Pertencem a essa categoria de direitos os interesses comuns dos membros de entidades associativas reconhecidas por lei, como sindicatos e associações profissionais.

Já os direitos difusos têm como característica mais acentuada a indeterminação de seus titulares e a inexistência de vínculo jurídico entre eles. Baseiam-se tais direitos em situações de fato, como consumir o mesmo produto, ou sujeitar-se aos mesmos fatores ambientais.

5 "Ao contrário dos direitos liberais, que são considerados uma garantia do indivíduo diante do poder do Estado, e ao contrário também dos direitos sociais, que consistem basicamente em prestações que o Estado deve ao indivíduo, o direito difuso ao meio ambiente consiste num direito-dever, na medida em que a pessoa, ao mesmo tempo em que é titular do direito do meio ambiente ecologicamente equilibrado, tem também a obrigação de defendê-lo e preservá-lo". In: BORGES, Roxana Cardoso Brasileiro. Processo, Ação Civil Pública e Defesa do Meio Ambiente: os direitos difusos em busca de uma concepção não-individualista de tutela e ampla legitimidade. In: Inovações em Direito Ambiental. Florianópolis: Fundação José Arthur Boiteux, 2000. p. 159. 
transindividuais, de natureza indivisível, de que sejam titulares pessoas indeterminadas e ligadas por circunstâncias de fato".

Segundo Rodolfo de Camargo Mancuso, os direitos difusos seriam caracterizados "pela indeterminação dos sujeitos, pela indivisibilidade do objeto, por sua intensa litigiosidade interna e por sua tendência à transição ou mutação no tempo e no espaço". 6

Eliseu Figueira diz, ainda, que "o interesse difuso é, portanto, o interesse de todos e de cada um, já que cada indivíduo dele é portador pelo facto de pertencer à pluralidade de sujeitos a que a norma confere tutela, e na medida em que todos se encontram inseridos numa dada situação objetiva". 7

Por sua vez, Teori Albino Zavascki afirma que os direitos difusos têm como características o fato de serem transindividuais e indivisíveis. ${ }^{8}$

Diante do exposto, parece restar claro que assimilar os direitos difusos em nosso sistema jurídico significa, antes de tudo, uma opção pela superação de um modelo estruturado sobre o individualismo, o patrimonialismo e a propriedade privada.

\section{CONSTITUIÇÃO DA REPÚBLICA E MEIO AMBIENTE}

O artigo 225 da Constituição Federal de 1988 denota uma postura de vanguarda em relação à preservação ambiental, conforme revela sua leitura: "todos têm direito ao meio ambiente ecologicamente equilibrado, bem de uso comum do povo e essencial à sadia qualidade de vida, impondo-se ao Poder Público e à coletividade o dever de defendê-lo e preservá-lo para as presentes e futuras gerações".

Para Ana Cláudia Bento Graf, "a Constituição de 1988, ao tratar do meio ambiente ecologicamente equilibrado como um direito fundamental do qual todos são destinatários e ao estabelecer a existência de um bem que tem duas características específicas, a saber, ser de uso comum do povo e essencial à sadia

${ }^{6}$ MANCUSO, Rodolfo de Camargo. Interesses Difusos: Conceito e legitimação para agir. 3. ed. São Paulo: Revista dos Tribunais, 1994. p. 115.

${ }^{7}$ FIGUEIRA, Eliseu. Renovação do Sistema de Direito Privado. Lisboa: Editorial Caminho, 1989, p.177.

${ }^{8}$ ZAVASCKI, Teori Albino. Defesa de Direitos Coletivos e Defesa Coletiva de Direitos. Revista Forense, V. 329. 
qualidade de vida, formulou inovação revolucionária, no sentido de criar um terceiro gênero se bem que, em face de sua natureza jurídica, não se confunde com os bens públicos e muito menos com os bens privados". ${ }^{9}$

\section{MEIO AMBIENTE COMO BEM JURÍDICO}

Aqueles bens que são de uso comum do povo e substanciais para a garantia da qualidade de vida são classificados como bens ambientais por Celso Fiorillo. Assim, o bem ambiental seria aquele que, além de ser de uso comum do povo, é essencial à qualidade de vida. Dessa maneira, o meio ambiente, "bem criado pela Constituição Federal de 1988 é, pois, um bem de uso comum, (...), um bem que pode ser desfrutado por toda e qualquer pessoa dentro dos limites constitucionais". ${ }^{10}$

De acordo com Carlos Marés de Souza Filho, ${ }^{11}$ são ambientais aqueles bens essenciais à manutenção da vida de todas as espécies, biodiversidade, e de todas as culturas, sociodiversidade.

Nas palavras de Ana Cláudia Bento Graf, "por tudo quanto se afirmou acima, sendo a água um bem de uso comum do povo e essencial à sadia qualidade de vida, não se the pode negar a natureza jurídica de bem difuso ambiental. Sua utilização, por este motivo, está condicionada à manutenção do equilíbrio ecológico do ambiente. Isto logicamente não quer significar que todo e qualquer uso implique um desequilíbrio juridicamente relevante, mas configura um limite fundado na sustentabilidade ambiental, que deve ser observado por todos, Poder Público e coletividade". $^{12}$

${ }^{9}$ GRAF, Ana Cláudia Bento. A Tutela dos Estados sobre as Águas. In: Águas: aspectos jurídicos e ambientais. Curitiba: Juruá, 2000, p. 54.

${ }^{10}$ FIORILLO, Celso Antonio Pacheco. O direito de antena em face do direito ambiental no Brasil. São Paulo: Saraiva, 2000, p. 55.

${ }^{11}$ SOUZA FILHO, Carlos Marés de. O dano ambiental e sua reparação. Curitiba, 1999, mimeo, p. 5.

12 GRAF, Ana Cláudia Bento. A Tutela dos Estados sobre as Águas. In: Águas: aspectos jurídicos e ambientais. Curitiba: Juruá, 2000. p. 55-56. 


\section{AQÜÍFERO GUARANI}

A existência do Aqüífero Guarani, um reservatório de águas subterrâneas que abrange quatro Países do Cone Sul (Argentina, Brasil, Paraguai e Uruguai), ${ }^{13}$ com potencial para diversos usos e relevante valor ambiental, social e econômico, impõe a imediata reflexão sobre o regime jurídico apto a regular, nacional e internacionalmente, 0 acesso a esses recursos hídricos e seus usos por todas essas Comunidades.

A preocupação com a água tem se intensificado por seus aspectos econômicos, políticos e administrativos, por sua relevância estratégica para o desenvolvimento regional e, sobretudo, por seus reflexos sobre os direitos humanos e a sustentabilidade socioambiental.

Ocorre que são muito distintas as diversas abordagens sobre a questão da água.

De um lado, existem aqueles que concebem o acesso à água como um direito fundamental do ser humano.

Entretanto, há aqueles que entendem a água como um bem econômico que, por diversas razões, precisa ser taxado. A cobrança seria vista como uma forma de conscientização para a importância da água, bem como um meio de se prevenir a escassez, estimulando o uso racional, por se tratar de um recurso natural que pode se esgotar. A água é considerada uma mercadoria negociável, de aspecto pecuniário, cuja utilização requer o estabelecimento de um preço justo. Contudo, a possibilidade de pagamento desse preço dividiria aqueles que têm e os que não têm acesso a tal bem.

Para Paulo de Bessa Antunes, o reconhecimento do valor econômico tem sido assumido desde a vigência do Código de Águas e ganhou nível constitucional desde a Carta de 34.

13 Sua área abrange 1.400 .000 quilômetros quadrados, dentre os quais 1 milhão está em território brasileiro. Acredita-se que ele constitua a maior reserva de água doce do mundo, com reservas de 45 mil quilômetros cúbicos (suficiente para abastecer de água toda a população mundial por alguns anos ou para abastecer uma população de 360 milhões de pessoas sem sofrer danos significativos). É constituído de várias rochas sedimentares da Bacia Sedimentar do Paraná, destacando-se o arenito Botucatu, caracterizado pela alta porosidade e permeabilidade. Sua água pode atingir temperaturas de até 50 graus Celsius, nas regiões em que ele está a mais de 1000 metros de profundidade, podendo ser utilizado para o lazer, a indústria, setor hospitalar e setor agrícola (combate à geada, p.ex.). Em quase sua totalidade, o teor médio de sólidos dissolvidos é 200 $\mathrm{mg} / \mathrm{L}$, considerado muito bom para consumo humano. 
Sendo assim, Paulo Affonso Leme Machado, ${ }^{14}$ ao tecer comentários sobre as associações de usuários e a gestão das águas leciona que: "A participação dos usuários do recurso hídrico nos organismos de administração desse recurso não é tarefa fácil de ser colocada em prática. Os usuários são pessoas físicas e pessoas jurídicas de direito público e de direito privado. Encontramos usuários concorrentes ou defendendo usos da águas opostos ou conflitantes entre si. Temos usuários situados a jusante e a montante de um mesmo curso d'água, com óticas às vezes diferentes, de um mesmo recurso a ser partilhado".

No Brasil, onde o colapso dos recursos hídricos, se houver, será ocasionado muito mais por uma falha de gestão da água do que por sua escassez, o primeiro posicionamento demonstra estar mais próximo da realidade e necessidade nacionais. O país precisa investir na educação ambiental e sanitária, na conservação e manutenção da infra-estrutura de abastecimento e na gestão compartilhada dos recursos hídricos, tanto no plano vertical, envolvendo as esferas federais, estaduais (há bacias hidrográficas que são estaduais) e municipais (o saneamento é de competência local), quanto no plano horizontal, envolvendo a integração dos próprios municípios e estados entre si, além dos setores que tratam do solo, das florestas, da agricultura, do ar etc.

Somente assim se fará a inclusão hídrica de mais de 40 milhões de brasileiros que não têm esse direito fundamental garantido.

A Constituição Federal prevê o direito à vida (art. $5^{\circ}$ ) e ao meio ambiente ecologicamente equilibrado (art. 225), sendo este considerado como "bem de uso comum do povo e essencial à sadia qualidade de vida". A água, sendo necessária para a sobrevivência e um dos componentes desse meio ambiente, pode ser considerada, então, como um direito fundamental e um bem de uso comum.

Dessa maneira, toda e qualquer análise ou proposta sobre o regime jurídico das águas subterrâneas deverá levar em consideração a noção de direitos fundamentais indisponíveis e a observância obrigatória desses direitos pela Comunidade Nacional e Internacional.

Isto posto, cumpre analisar, brevemente, a legislação brasileira sobre a temática ora abordada.

\footnotetext{
14 MACHADO, Paulo Affonso Leme. Direito Ambiental brasileiro. 6. ed. São Paulo: Malheiros, 1996. p. 351.
} 


\section{CÓDIGO DE ÁGUAS - DECRETO FEDERAL N. 24.643/34}

Este Código alterou significativamente os dispositivos legais do Código Civil brasileiro vigente à época, principalmente no que se refere à regulamentação do regime dominial e de uso das águas no Brasil. As águas passam a ser, então, um dos elementos básicos do desenvolvimento, pois a eletricidade é um subproduto essencial para a industrialização do País. ${ }^{15} \mathrm{O}$ governo pode intervir a qualquer momento, autorizado por este dispositivo legal, quando entender necessário à garantia da qualidade e salubridade dos recursos hídricos. As águas passam a ser vistas como um recurso dotado de valor econômico para a coletividade, e, desta forma, merecedora de atenção especial do Estado. Cabe, ainda, ressaltar que os artigos 96 ao 101 do Código de Águas, no Título IV, dispõem sobre as águas subterrâneas.

\section{CÓDIGO FLORESTAL - LEI FEDERAL N. $4.771 / 65$}

Prevê a manutenção de vegetação de preservação permanente ao longo de rios, para evitar a erosão das terras e o conseqüente assoreamento dos cursos d'água, ao redor de lagoas, lagos e reservatórios d'água, nas nascentes e olhos d'água.

Este Código tem como preocupação preliminar a preservação da mata ciliar, dada sua importância no deflúvio superficial e no deflúvio de base. Ou seja, sua remoção implica a redução no intervalo de tempo entre a queda da chuva e os efeitos nos cursos d'água, diminuindo a capacidade de retenção da água nas bacias hidrográficas e aumentando o pico das cheias. Além disso, a cobertura vegetal serve como limitação à possibilidade de erosão do solo, minimizando a poluição do curso d'água provocada por sedimentos.

${ }^{15}$ ANTUNES, Paulo de Bessa. Direito Ambiental. Rio de Janeiro: Lúmen Juris, 1996. p. 269. 


\section{Lei Federal n. 6.225/75 sobre a proteção do solo e combate à erosão}

Esta Lei dispõe sobre discriminação, pelo Ministério da Agricultura, de regiões para execução obrigatória de planos de proteção ao solo e de combate à erosão e dá outras providências.

\section{Resolução 20/86 do Conselho Nacional do Meio Ambiente - CONAMA}

Esta Resolução estabelece a classificação das águas em doces, salobras e salinas, com base nos usos preponderantes, estabelecendo o nível de qualidade a ser alcançado e / ou mantido em um corpo d'água ao longo do tempo, sendo as águas doces aquelas com salinidade igual ou inferior a $0,50 \%$, as salobras com salinidade igual ou inferior a $0,50 \%$ e $30 \%$, e as águas salinas aquelas cuja salinidade é igual ou superior a $30 \%$.

\section{Lei Federal 9.433/97, que instituiu a Política Nacional de Recursos Hídricos e criou o Sistema Nacional de Gerenciamento de Recursos Hídricos}

Segundo esta Lei, a matéria do Gerenciamento de Recursos Hídricos está disposta na previsão legal do Relatório sobre a Situação dos Recursos Hídricos, que deve conter o prognóstico sobre a disponibilidade futuro dos recursos, em quantidade e qualidade, mantidas as atuais tendências de uso e procedimento gerenciais, e no Plano de Recurso Hídrico, que deve conter metas de racionalização de uso e propostas para a criação de áreas sujeitas à restrição de uso, com vistas à proteção do recurso hídrico.

São integrantes do Sistema Nacional de Gestão de Recursos Hídricos o Conselho Nacional de Recursos Hídricos, o Comitê Intersetorial, os Comitês de Regiões Hidrográficas, os Comitês de Bacia Hidrográfica e as Agências de Bacia Hidrográfica.

O Conselho Nacional de Recursos Hídricos, composto pelo Comitê Intersetorial e pelos Comitês de Regiões Hidrográficas, tem como principais funções o estabelecimento de diretrizes suplementares para a implantação da Política Nacional de Recursos Hídricos, a arbitragem administrativa dos conflitos existentes 
entre os Comitês que o compõem, aprovação do Relatório Nacional sobre a situação dos recursos hídricos, aprovação do Plano Nacional de Recursos Hídricos, acompanhamento da execução do Plano Nacional de Recursos Hídricos, análise das propostas de alteração legislativa relacionada aos recursos hídricos, deliberação sobre projetos de aproveitamento e, por fim, aprovação do plano de trabalho e do orçamento da Secretaria Executiva.

O Comitê Intersetorial, composto por doze representantes do Poder Executivo federal e dozes representantes de organizações da sociedade civil, tem como principais atribuições a informação ao Conselho Nacional de Recursos Hídricos dos condicionantes que são impostos ao planejamento e à gestão dos recursos hídricos pelos planejamentos nacional e regional, informação aos setores usuários dos condicionantes existentes ao uso dos recursos hídricos, proposição ao Conselho Nacional de diretrizes adicionais e a supervisão do Sistema de Informações sobre Recursos Hídricos.

Os Comitês de Região Hidrográfica (Região Hidrográfica da Amazônia, Região Hidrográfica Nordestina e Região Hidrográfica Centro-Sul) têm competência para arbitrar administrativamente os conflitos existentes em um Comitê da Bacia Hidrográfica ou entre os Comitês, aprovar, divulgar, acompanhar e executar o Relatório e o Plano de Recursos Hídricos da Região Hidrográfica, analisar os projetos de aproveitamento dos recursos hídricos que extrapolam a área da região hidrográfica, e deliberar sobre os projetos de aproveitamento dos recursos hídricos cuja repercussão extrapola a bacia hidrográfica de sua implantação.

A principal competência dos Comitês de Agências de Bacia Hidrográfica é a arbitragem administrativa dos conflitos relacionados aos recursos hídricos, aprovação, divulgação e atualização dos relatórios sobre a situação dos recursos hídricos, aprovação do Plano de Recursos Hídricos, acompanhamento da execução deste Plano, definição das derivações, captações e lançamentos para a isenção de obrigatoriedade de outorga de direitos de uso dos recursos, efetivação do enquadramento dos corpos de água em classes de uso, ratear o custo das obras de uso múltiplo ou de interesse comum ou coletivo, estabelecimento dos valores a serem cobrados pelo uso de recursos hídricos e suas respectivas multas por inadimplência, e, finalmente, aprovação do plano de aplicação dos recursos arrecadados. 
A Agência de Bacia Hidrográfica deve atuar em conjunto ao Comitê da Agência da Bacia Hidrográfica, devendo aquela fiscalizar a atividade de arrecadação financeira e a aplicação dos recursos arrecadados.

\section{Portaria 1469/00 do Ministério da Saúde sobre o direito à água potável}

Esta Portaria estabelece que toda água destinada ao consumo humano deve obedecer ao padrão de potabilidade e está sujeita à vigilância da qualidade da água.

Isto posto, cumpre, também, salientar que ainda não existe regulamentação da água em âmbito universal, seja através de tratados, seja através de resoluções obrigatórias. Toda a discussão em torno do assunto se resume a posicionamentos, por vezes distintos, das mais diversas organizações internacionais, de caráter inter ou não-governamentais. Seguem as principais manifestações.

\section{$1^{\circ}$. Fórum Mundial da Água, 1997, Marrakesh}

Defesa da água como bem econômico.

\section{$2^{\circ}$. Fórum Mundial da Água, 2000, Haia}

A principal decisão tomada neste Fórum da Água foi a elaboração de uma declaração ministerial que considera a água vital para a vida e a saúde das pessoas e ecossistemas e um requisito básico para o desenvolvimento das nações, embora, em todo mundo, mulheres, homens e crianças ainda sofram com a falta de acesso à água segura e adequada para atender suas necessidades básicas. Na declaração, os 130 países presentes ao fórum comprometem-se a buscar alternativas e a promover mudanças em suas políticas de recursos hídricos, de forma a manter a segurança da água para o século 21. Em outras palavras, isso significa assegurar que a água doce, os recursos costeiros e ecossistemas associados à água sejam protegidos e recuperados; que o desenvolvimento sustentável e a estabilidade política devem ser promovidos; que qualquer pessoa deve ter acesso à água segura e suficiente a um custo compatível com manutenção de uma vida produtiva e saudável. 


\section{$3^{\circ}$. Fórum Mundial da Água, 2003, Kyoto}

O acesso à água será de todos apenas se a iniciativa privada gerenciá-lo, pois só ela detém o capital necessário. Na ocasião, também se fez um importante alerta sobre a situação dos aqüíferos e das águas subterrâneas, para os quais praticamente não há políticas de conservação que garantam a recarga e o controle da contaminação. Os casos mais graves são dos aqüíferos dos Estados Unidos, México, Índia, China e Paquistão, mas também há crise em algumas partes da Europa, África e Oriente Médio. Estima-se que, hoje, 1,5 bilhão de pessoas depende das águas subterrâneas para seu abastecimento.

\section{Fórum da Água Potável, 2003, Dushanbe}

O evento pretendeu servir como uma plataforma aos países para discutir sobre como criar as condições necessárias ao melhoramento das fontes de água para as próximas gerações. Os principais tópicos discutidos foram: água e cooperação interestatal; água, saúde e sanitarismo; conservação da água e produtividade na agricultura; parcerias no tratamento da água; e, relatórios e recomendações com soluções dos problemas relativos à água.

\section{Rio +10 - Cúpula de Joanesburgo}

Foram propostas as "Metas do Milênio" de redução pela metade da população sem acesso à água potável (aproximadamente 1,4 bilhão de pessoas) e sem sistema básico de saneamento (2,3 bilhões de pessoas), até o ano 2015.

\section{Comitê de Direitos Econômicos, Sociais e Culturais em 2002}

Definiu a água como direito humano, e bem social e cultural, nos termos do "Comentário Geral", que interpreta a norma do Pacto Internacional sobre Direito Econômicos Sociais e Culturais, de novembro 2002: $A$ água deveria ser tratado como um bem social e cultural e não como uma mercadoria econômica. A água é fundamental para a vida e saúde. O direito humano À água é indispensável para ter 
uma vida saudável e com dignidade humana. É um pré-requisito para a realização de todos os outros direitos humanos.

\section{Rio 92 e Agenda 21}

A Agenda 21 foi um documento elaborado na Rio 92, o qual compreende um plano de ação a ser efetivado global, internacional e nacionalmente, pela ONU, pelos Estados, pelas ONGs e pelos próprios cidadãos. Suas Declarações foram adotadas por mais de 178 países. No que tange à água, especificamente, a principal recomendação é a de ao desenvolver e usar os recursos hídricos deve-se dar prioridade à satisfação das necessidades básicas e à proteção dos ecossistemas. Entretanto, uma vez satisfeitas essas necessidades, os usuários da água devem pagar tarifas adequadas.

\section{Programa da ONU para o Meio Ambiente - PNUMA}

Sem água potável adequada não há saída possível para a pobreza. No sítio eletrônico da Divisão para Desenvolvimento Sustentável da ONU há vasto material acerca da água como Direito Humano fundamental.

\section{Agência Internacional de Energia Atômica - AIEA}

Há uma quantidade limitada de água doce sobre o nosso plante e não podemos continuar a agir como se ela nunca viesse a faltar. O relatório elaborado pela Agência, em parceria com a ONU, chega à conclusão de que, em 2005, se o consumo desenfreado e desregulado de água continuar, haverá pessoas vivendo em áreas de difícil acesso a água potável, quando não impossível.

\section{FAO}

Estudos indicam que um em cada cinco países em desenvolvimento vai sofrer a escassez de água até 2030, diminuindo a produção de alimentos tendo em vista que a agricultura consome aproximadamente $70 \%$ de toda a extração de água. Desta forma, a agricultura é essencial na ajuda da resolução dos problemas 
relativos à água. Isto porque a agricultura é a maior consumidora de água. Ela utiliza-se de cerca de $70 \%$ de toda a água potável no mundo. Com o crescimento da população mundial a agricultura terá que aprender a usar a água mais eficientemente.

\section{OMC}

Assuntos relativos ao meio ambiente, o desenvolvimento sustentável e o comércio têm sido debatidos no GATT e na OMC há anos. Desde 1995, o Comitê de Comércio e Meio Ambiente tem trabalhado nestes tópicos. Na 4a Conferência Ministerial em Doha, 2001, os Ministros presentes concordaram em iniciar negociações sobre o tema. Há projetos de regulamentação que tratam a água como mercadoria, através da reforma que se pretende fazer sobre o GATTS.

\section{Banco Mundial}

O Banco Mundial elaborou material denominado "Água Brasil", disponível em formato PDF no sítio eletrônico do próprio Banco. O documento discute alguns dos enormes desafios presentes na agenda do setor água, à luz das experiências passadas e das lições aprendidas na história recente deste setor no contexto brasileiro. Segundo o BM e seus relatórios, a água é prioridade para o crescimento responsável com redução da pobreza.

\section{FMI}

Dos 40 países que receberam empréstimos em 2000, 12 assinaram acordos que traziam condições sobre os serviços de água, normalmente sobre privatização. Segundo relatórios desta Organização, os países pobres precisam de mais acesso e controle externo sobre bens essenciais (como a água, saúde, educação e saneamento) a fim de escapar da pobreza. 


\section{NAFTA}

Observe-se que o NAFTA exige a liberação governamental do controle de seus suprimentos domésticos de água para que seja possível participar do bloco.

\section{$1^{\circ}$. Fórum Alternativo Mundial da Água}

Realizado em Florença, 2003, este Fórum propôs à ONU a realização de um "Contrato Mundial da Água", em que a água seria declarada como um direito humano, além da criação de uma Autoridade Mundial da Água, com funções jurídicas, legislativas e de controle do financiamento público e dos programas de investimentos em serviços hídricos. Iniciativas como o "Sede Zero" ("para que nos próximos vinte anos esteja garantido a todos os habitantes da terra o acesso à água") e a "Campanha pela declaração da ilegalidade da pobreza" (porque "banir a pobreza significa apoiar as campanhas em andamento contra a construção de grandes represas e obras grandiosas, privilegiando intervenções sustentáveis em nível local que não ameacem com altos riscos tecnológicos, sociais, humanos e ambientais; inspirados nos princípios de precaução e de respeito da natureza') concretizam a idéia proposta no encontro.

\section{Fórum Social das Águas}

Aconteceu na América Latina (São Paulo-Brasil, em março de 2003), África, América do Norte, Europa e, também, um Fórum Mundial, juntamente com o Fórum Social Mundial, na Índia, em janeiro 2004.

Considerando a necessidade de introduzir a questão social nas discussões mundiais sobre a gestão das águas, como recurso natural cujo acesso e manejo deve ser economicamente viável, ambientalmente sustentável, mas socialmente justo, é que o Movimento Grito das Águas, no Brasil, e a International Global Water Coalition (IGWC), com sede na França, resolveram realizar o evento. 


\section{Fundação Mário Soares}

Propõe a criação de uma "Rede de Parlamentares pela Água", de um "Observatório mundial dos direitos da água", encarregado de recolher e divulgar informações sobre o assunto, bem como a celebração de um "Tratado mundial da água”, fundado na idéia de água como bem vital patrimonial comum da humanidade, excluindo a possibilidade dela figurar em qualquer convenção internacional comercial, como acontece com o patrimônio cultural.

\section{Conselho Mundial de Água (WWC)}

Relatório elaborado por Michel Camdessus (ex-presidente do FMI) e que dispõe sobre financiamento de instituições públicas em conjunto com as privadas, duplicação dos investimentos dos Governos na água e otimização dos mercados locais e regionais. Os resultados práticos de todas as discussões, argumenta 0 Conselho Mundial de Água, dependem bastante da política adotada pelos governos, que, segundo a organização, têm a responsabilidade de agir em defesa do meio ambiente e do desenvolvimento sustentável.

\section{CONCLUSÃO}

O tratamento legal brasileiro dado às águas passa, numa divisão de cunho didático, por três momentos: Privado, Econômico e Coletivo-Econômico. Essas mudanças na lei decorrem da mudança de racionalidade do momento histórico vivenciado.

A Idade Moderna inicia-se com a derrocada do poder papal, do feudalismo e ascensão da burguesia. A ciência moderna abandona os dogmas teológicos e elege a razão como seu núcleo. Essa ideologia liberal-burguesa consagra a economia de mercado e influencia o direito, principalmente, com a idéia de sistema jurídico, sendo a codificação a expressão máxima da "naturalização" do direito. Tal fenômeno pode ser observado nos códigos oitoscentistas - Código de Napoleão de 1804 e Código Alemão de 1836 - de cunho antropocêntrico, individualista, e calcados no tripé Família, Contrato e Propriedade, que influenciaram o Código Civil 
brasileiro. Mas a Constituição Federal de 1988 vem dar um cunho mais social ao direito, aos moldes da Constituição de Weimer, onde estão presentes valores como segurança coletiva, justiça social e bem comum.

Surgem neste século dois grandes movimentos, o da Constitucionalização do Direito e o da Especialização da Legislação, que garantem interesses coletivos e difusos. Tal mudança ocorre não somente no sujeito de direito, mas também no próprio objeto.

Os direitos difusos vêm sido positivados nas novas constituições, como a espanhola de 1976, a portuguesa de 1978 e a brasileira de 1988, cuidando basicamente da proteção ambiental, cultural e do direito de minorias hiposuficientes.

Os direitos difusos são aqueles que visam à proteção de certos interesses que não se inserem perfeitamente no standard individualista cunhado pela modernidade, mas representam uma projeção de anseios sociais pela tutela de bens que não são nem meramente individuais nem sequer simplesmente coletivos, mas, sim, paradoxalmente, pertinentes a cada ser humano e a todos ao mesmo tempo. Pode-se mesmo dizer que a principal nota característica dos direitos difusos seja, justamente, como a sua própria denominação já está a sinalizar, o fato de eles não se concentrarem na noção de um sujeito que, por ser seu titular, esteja apto a deles dispor segundo a sua vontade, mas possuírem uma verdadeira titularidade difusa. Essa titularidade é difusa de tal forma que a alguns direitos difusos, como 0 direito a um meio ambiente equilibrado, reputa-se o caractere de herança intergeracional: ao ordenamento jurídico, mais que apenas preocupar-se com os homens do presente, impõe-se também a tutela dos interesses dos homens do futuro. É dessa forma que a presente pesquisa vislumbra a relação entre o homem e o meio ambiente. Fenômenos próprios da contemporaneidade como a industrialização, a urbanização e o elevado crescimento populacional demonstram que os recursos hídricos, até há bem pouco tempo considerados inesgotáveis, não o são. Dessa forma, é urgente que a política de aproveitamento dos recursos hídricos e a gestão do Aqǘfero Guarani esteja em consonância com a disciplina constitucional do meio ambiente, direito fundamental que é uma projeção do direito à vida, que, nos termos do Art. 225, considera-o como um "bem de uso comum do povo" e impõe tanto ao Poder Público quanto à coletividade "o dever de defendê-lo e preservá-lo para as presentes e futuras gerações". 
Para além da cega visão mercantilista, o trabalho ora apresentado faz ecoar o grito das lutadoras e lutadores do povo que combatem, dia a dia, a sede de água e de direitos e que buscam, ao menos, uma gestão do Aqüífero Guarani comprometida com os direitos humanos e com a sustentabilidade socioambiental, em que o direito fundamental à água seja marcado por sua titularidade difusa.

\section{BIBLIOGRAFIA}

ANTUNES, Paulo de Bessa. Direito Ambiental. Rio de Janeiro: Lúmen Juris, 1996.

BOBBIO, Norberto. A Era dos Direitos. Tradução de Carlos Nelson Coutinho. 12. ed. Rio de Janeiro: Campus, 1992.

BORGES, Roxana Cardoso Brasileiro. Processo, Ação Civil Pública e Defesa do Meio Ambiente: os direitos difusos em busca de uma concepção não-individualista de tutela e ampla legitimidade. In: Inovações em Direito Ambiental. Florianópolis: Fundação José Arthur Boiteux, 2000.

CLARKE, R. \& KING, J. The Water Atlas. New York: The New Press, 2004.

FIGUEIRA, Eliseu. Renovação do Sistema de Direito Privado. Lisboa: Editorial Caminho, 1989.

FIORILLO, Celso Antonio Pacheco. O direito de antena em face do direito ambiental no Brasil. São Paulo: Saraiva, 2000.

GRAF, Ana Cláudia Bento. A Tutela dos Estados sobre as Águas. In: Águas: aspectos jurídicos e ambientais. Curitiba: Juruá, 2000.

MACHADO, Paulo Affonso Leme. Direito Ambiental brasileiro. São Paulo: Malheiros, 6 ed, 1996.

MANCUSO, Rodolfo de Camargo. Interesses Difusos: Conceito e legitimação para agir. 3. ed. São Paulo: Revista dos Tribunais, 1994.

SILVA, José Afonso da. Direito Ambiental Constitucional. São Paulo: Malheiros, 3 ed, 2000.

SOUZA FILHO, Carlos Marés de. O dano ambiental e sua reparação. Curitiba, 1999.

ZAVASCKI, Teori Albino. Defesa de Direitos Coletivos e Defesa Coletiva de Direitos. Revista Forense, v. 329. 